\title{
Analysis on the Relationship Coordination Between Wildlife Protection and Sustainability
}

\author{
Minjin Chen ${ }^{1}$ \\ 'Shantou Chaoyang Experimental School, Shantou, Guangdong515800, China \\ E-mail: 2944879676@qq.com
}

\begin{abstract}
Since reform and opening-up, individuals and government paid more and more attention on the significance of protecting wildlife and sustainable development. Facing with severe problems brought by environment and ecology, human beings start to reflect their attitudes and behaviors towards animals and surroundings. However, in the past hundreds of years, humans have hunted billions of wildlife and destroyed their habitats for predation, leather collection, industrialization, resource exploitation etc, all of which directly lead to a rapid decline on the quantity or even extinctions of species. Though individuals gradually realized and reflected the mistakes they've made, illegal hunting still exists. In this case, the whole ecological system is in great danger and it is an onerous challenge to make helpful contributions. Individuals around the world unaware of their influence on protecting sustainability. Therefore, a method to better coordinate the relationship between animals conservation and sustainability should be came up with.
\end{abstract}

Keywords: Wildlife, protection, sustainability, harmony, ethic, species diversity

\section{INTRODUCTION}

To effectively improve the environment and protect species diversity, governments have carried out strict policies and laws. For example, The Law of the People's Republic of China on the Protection of Wildlife and Environmental Protection Act were amended for plenty of times according to social situations and public reflection in different periods. But there's no doubt that depending on laws and rules is insufficient to completely coordinate the relationship between human beings and the nature. To prompt wildlife conservation becoming more and more mature and in-depth, value propositions of ethic and ideas should be involved. However, are ethic and policies enough to solve the root social problems? It is actually still a long way to go. Therefore, this article will fundamentally put forward some valid solutions to further wildlife and environmental protection.

\subsection{Discussion on the Meaning of Wildlife Protection Based on Sustainable Development}

It should be admitted that sustainable development is an inevitable choice for forestry development. This is because forestry is the most complicated and abundant resources, including forests, woods and many other biological resources. Specifically, forestry provides human beings with woods, medicinal materials and feedstuff, while preserving soil and water and purifying air at the same time. Besides, forestry plays a beneficial role in maintain biological diversity. Forestry management aims at promoting the development of renewable organisms and further offering humans more economic and ecological benefits.[6]

Human beings, animals, vegetation and other natural resources constitute our living environment. Protecting and rationally exploit wildlife resources maintain ecological balance, improve natural environment and accelerate the development of social economy. Sustainability is based on the harmonious development of society, economy, population and resources, which satisfies contemporary demand while would not be harmful to future generations. Human beings should learn to establish new moral and value proposition for wildlife protection as well as for human survival.[7]

\subsection{Current Situation of Wildlife Parks}

At present, with the continuous growth of human population and progress of science and technology, human's control over nature has led to more intensive pressure on the natural environment. In this case, the living environment of wild animals has been greatly threatened, as well as having the surroundings of 
conservation area being deteriorated increasingly. The conservation of wildlife has already been a basic policy in China, but wild animals, especially endangered species are dwindling their number annually. This is because people's mindset for resources plundering is still intense and even stubborn, a situation without considering the result of wild animals resources abundance.

As for the development of wildlife parks, there are exactly five main problems in total. First of all, there are still some misunderstanding towards the meaning of wildlife parks. In China, a large amount of people tend to believe that wildlife parks means species abundance or area expansion, without considering investment and return, operating expenses, animal preservation and so on As a result, a rush and blind phenomenon of investment takes place in China. Secondly, the development of such parks lack of the restriction of law and policies. In China, the responsibility of wildlife protection actually belongs to forestry administration department, while the specific investment, construction and operation refers to departments of tourism, environmental protection and city building. And in fact, forestry administration department only has the right to examine import and export of animals and their domestication and breeding. Such complicated management system gradually undermine the force of supervision towards wildlife parks. Thirdly, the function of ex-situ conservation did not come into play. High technology and sufficient investment are in need for ex-situ conservation, but plenty of wildlife parks are short of professional technicians. It is said that from a survey of 18 wildlife parks, the maximum proportion of technicians takes up $30.8 \%$, as well as having the minimum accounting for only $2.8 \%$. In this case, without enough technicians and support from government, the development of ex-situ conservation cannot work out successfully. Fourthly, the animal welfare is poor. A bulk of wildlife parks make up large area indeed, but the reformation of environment is committed to human beings, rather than animals. Therefore, a vast majority of individual animals can be only kept in cages. Lastly, some wildlife parks still exist safety hazard. News like a technician is unfortunately killed by two lioness can be heard from television from time to time. This is because some managers of wildlife parks turn a dense seine into a sparse fence to attract more visitors. As a result, accidents would take place.[5]

\subsection{Changes in Ethics}

In the 1950s and 1960s, anthropocentrism intensively dominated Chinese governments and individuals' world view. This idea considered interests of human-beings as a supreme criterion, which even came up with an idea that the improvement of civilization was built on man's conquest of nature.In this case, being affected by anthropocentrism, people started to fiercely kill billions of animals and destroyed their habitats for self-interest.
As a result, a vast majority of wildlife such as dodo, quagga, thylacinus cynocephalus died out because of human activities.

In the late 20th century, confronted with severe problems brought by economic development and ecological imbalance, human beings eventually reflected what they had done and was aware of biological equality. Therefore, biocentrism that stood at the opposite side of anthropocentrism finally came out. At that time, people firmly believed that all creatures including animals and vegetation had their intrinsic values and should be treated with equal respect. Biocentrism effectively promoted human-beings to learn to esteem and revere the nature, but the idea ignored each individual life and showed disavowal of man's direct obligation to species and ecosystems [1].

Fortunately,in the 21 st century, the communist party of China carried out the idea of sustainability, which focused on fairness and harmony. The concept presented that people definitely had their rights to make use of natural resources to satisfy the needs of survival, but within the limitation of natural baseline. Humans should always stood in personal footing to be friendly and get along well with any species [2].

From the above, conclusion that with the development in different periods, human beings are altering their minds and attitudes towards wildlife and environment finally worked out. Humans are becoming more and more mature and impartial, which positively brought favorable social atmosphere and changed people's lifestyle to a certain extent.

\subsection{Juveniles' Consciousness towards Animal Protection}

Even though government bolster the ideas of environmentally friendly and species diversity, is it a helpful way to encourage individuals to take actions.Actually, teenagers nowadays are those who can considerably influence eco-concervation perspective since the quantity of teenagers in China takes up a really large proportion,with its figure reaching about 250 million.Consequently, emphasizing on teenagers' ecomorality education is an inescapable task for both governments and educators.

As early as 2015, the results of pupils' questionnaire surveys witnessed their real inner world towards wildlife. According to a questionnaire about animal protection, $87.4 \%$ pupils specifically claimed that every species was one of us and human-beings ought to live in harmony with all creatures around the world. However, there were still $8.4 \%$ students showed indistinct attitudes and $4.2 \%$ presented unwillingness of getting alone well with wildlife.As for another research, 5.3\% pupils represented indifferent manner, and they believed that there would be 
no negative impacts if humans eat wildlife from time to time [3].

As can be seen, though a vast majority of students were sensible enough to take protecting wildlife and environment into consideration, there were still a few of them did not realize the significance of animals and environment for human-beings. A small number of interviewees expressed a confused or even repulsive manner to the relationship between individuals and animals, plus wildlife and environment. They supposed the conservation of wildlife and sustainability could never be changed by individuals' endeavor but governments' rules.

Therefore, it could be obviously concluded that schools lack of educational activities or lessons about ecological ethics. By investigating about the frequency of schools to hold such educational activities, a terrible consequence could be found. A large amount of students exposed educators' indifference about environmental and wildlife protection so they seldom received relevant knowledge at school, and the figure of students was severely being $53.1 \%$, more than a half [3].

Although every school nowadays has various models and ways to regulate their educational systems, but the course design of involving the utility about ecological protection is still scarce. Schools now pay great attention to subjects like natural biology, science, math and other courses that have little relevant knowledge about ecoconservation and wildlife protection. As a matter of fact, lessons such as linguistics and politics should take greater responsibility to improve the contents of the texts or materials by adding some in-depth articles related to ecology. Moreover, science experimental courses make insufficient efforts to ecological protection. Schools and teachers should make full use of the advantages of such courses to stimulate students to be a participation through their hands and brains personally.

\subsection{People's Ideas towards Wildlife and Sustainability}

After learning about the current attitudes of juveniles, a relatively undesirable consequence ultimately attained. In this case, looking into nowadays people's concept about wildlife and sustainability and find out the root because the problems are necessary.

According to my online investigation about people's thinking of animals protection and environment, a deeper understanding of current awareness finally came across. There were in total 23 people took part in the interview, which specifically consisted of 20 teenagers and 3 middle-aged people. For the question about the relationship between humans and animals, 19 people stood the idea that both human-beings and animals had equal status to each other and should definitely live in harmony, while another 4 person referred that the menace brought by wildlife could be a great danger and even supposed that humans had their rights to dominate animals' life. In addition, from other questions, there was only 1 person believed wildlife nowadays lived in satisfying and healthy conditions and circumstances; 9 person were reluctant to report illegal hunting or other harmful actions if they were witnesses; 13 of them honestly expressed their little understanding about The Law of the People's Republic of China on the Protection of Wildlife and Environmental Protection Law of the People's Republic of China; and surprisingly, there were still 2 did not heard of the laws at all.

In terms of the methods to coordinate the relationship between wildlife conservation and sustainability, almost everyone was aware of the importance of pollution treatment, whose ideas uniformly endorsed that we should develop economic while make an effort to maintain a environmentally friendly society. People have excellent understanding of that the effort came from individuals themselves rather than government only and they even knew about how to properly solve those social problems. By refuting and reporting those illegal acts in time to government and organizations, carrying out lowcarbon development, officially publishing journals to remind individuals, and all of these methods were in wonderful comprehension [4].

But why the current situation and social problems are still extremely serious? Actually people are willing to make contributions to wildlife and sustainability protection in daily life. And they are able to know and concern about the problems and news through television, newspapers, the Internet, smart phone applications and so on. But the root problem came from people's morality itself. They are too indifferent to care about whether there are someone hurting wildlife around the world or around them. They know they can make positive changes if they take actions, but in most cases they don't want to be "officious". It is actually quite reasonable since everyone has their jobs and work every day so they tend to pay little attention and vigor to make an effort in person. Protection is just too far away from them because they seldom browse news about such social problems. Everyone tends to focus on their occupations and families only since there are now still a giant amount of people laboriously struggling with their life.

\subsection{Newly-built Business Model}

We now absorb the reasons for people's reluctance to make an effort in person come from unfamiliarity and indifference.

In this case, a newly-built business model could be came up with. The value proposition of such new model aims at promoting close connection between humans and wildlife and environment. First of all, it is a platform which can be found on almost every application, such as official accounts on Wechat and Microblog and 
advertisements while browsing news on some certain apps. By offering more chances for internet users to take in the information such as species diversity and contamination treatment, one can spend more time to learn deeper about this programme so that the possibility of individuals to make contributions increases. Secondly, the platform provides opportunities to donate money and be a volunteer though taking care of animals or helping pollution treatment personally. Once taking part in volunteer service, individuals can definitely stay in close contact with specific animals and get better understanding of their life to a large extent. Taking pandas as an example, customers taking a chance to look after pandas might because of their lovely appearance. But if pandas walk into their life, they will then find that it could be a huge challenge in fact. Each panda has to eat approximately 25 kilograms bamboo every day, so volunteers ought to decide proper time and quantity to feed them. Besides, pandas' physical health is likely to be influenced by the climate, feeding ways and health conditions, like their teeth tend to be abraded since they have long-term habit of eating bamboo. Above all, the business model creates a harmonious relationship between sustainability minded groups and engineering firms. It works as a media and agency to coordinate with their work. Sustainability minded groups are sometimes obligated to guarantee the safety of animals' habitats, so the platform would organize meetings to come up with a win-win method which helps to effectively coordinate both work to a large extent. In this case, companies are capable to finish their work peacefully and morally. As a result of the functions brought by the platform, everyone is able to stay closer to our surroundings and show more concerns to animals and environment.

Frankly speaking, such business model could be divided into three specific models-platform model, sustainability model and market intermediary models. And to better maintain the new model, certain person should be targeted. In addition to cooperating with engineering firms and sustainability minded groups, the platform also needs to work as an agency to mediate volunteers and local institutions who organize opportunities for volunteer service. Besides, advertiser companies and governments are significant cooperators to effectively disseminate the value proposition of species diversity and sustainability since they tend to think of valid solutions to popularize an idea.

Anyway, it could never be an easy or relaxing mission to operate and manage a successful platform. To begin with, the division of assignment and labor is utterly indispensable. For instance, there must be employees taking the responsibility to communicate and get alone well with customers, so basic communication skills are requisited. One ought to learn to listen carefully to clients,be polite and professional all the time, never impose self ideas to clients and always try to think about the intention of each customers' question. The most crucial one is to cater for customers' needs and offer the most comfortable service throughout the whole process. Moreover, to get closer connection with customers, the platform have to think out some operation tools, such as smart clients, inquiry management and conversion of incomplete transaction. By making full use of such tools, personal information of customers like date of birth and email address could be obtained, which remarkably help to improve the efficiency of offering more precise service and seek for valuable customers. But foremost, the quality guarantee is the fundamental work that could never be neglected, which is absolutely the best quality to attract customers and weapon competitors. Also, by operating regular innovation that consists of technique and neoteric service, the platform is able to gain optimization and keep pace with customers all the time.

All in all, it is an ideal business model that needs every assignment to well match up. And if such dream model come true in the end, the whole society could ultimately turn into a real peaceful and harmonious world.

\section{CONCLUSION}

Throughout the whole passage, it was clearly noted that human-beings still lack of internal consciousness, even though their ideas and ethic are getting more and more faultless. In most cases, people choose to stay away from making contributions themselves due to selfish desire so that they lose the capability to control themselves and sometimes could not even realize what they have done might hurt animals and economy to a large extent.

Only if individuals attach importance to selfdiscipline from the bottom of their hearts can the society truly provides wildlife and vegetation with better environment and vivosphere.

Governments should try best to disseminate ecology theory to every household, guiding individuals especially teenagers to have proper behaviors and clear discrimination of right and wrong. Setting up a new ideal business model helps to bring human and ecology together as well, which considerably appeal to animal caring and environmental protection.

All in all, in spite of strict policies and various publicity, individuals should learn to manage selfbehaviors at every moment and do the best to make an effort for a harmonious society.

\section{ACKNOWLEDGMENT}

I am really graceful to my professor Mathew, who patiently interpret detailed principles about each entrepreneurship and potential social problems behind it. And I also want to say thank to everyone taking part in the study because they are so altruistic that they share about their ideas and viewpoints freely and tend to offer 
timely suggests to me, which effectually help me to get better understanding of every knowledge point.

\section{REFERENCES}

[1] N. Sun, Study on the protection of wild animals in China from the perspective of the ecological ethics.Master's thesis of Zhongyuan engineering institute, 2017.

[2] N. Cai,2016.Wildlife and the exploitation of natural reserve. Periodical.(2016) S863.A.1003-6997 320061-01.

[3] L. Lu, Investigation on Wildlife Protection Status and Countermeasure of Elementary School Students in Parts of China. Chinese Journal of Wildlife. (2016) 37 (2): $166-171$.

[4] W. Wang, The ethical basis of wildlife protection.Sichuan Journal of Zoology. (2006) Q16.A.1000-7083(2006)04-0786-02.

[5] X. Yang, Problem in Development of Wildlife Parks in China and Strategies of their Sustainable Development.Chinese journal of Wildlife. (2008) Q95-339.A.29(3):152-156.

[6] H. Wang, Discussion on rational exploitation of wild animal resources.Exploration of forestry reform. (1999).138 (2).

[7] J. Chen,YHCC.Discussion on modification of wildlife protection law based on sustainable development.886D8(688)68D66D6. 